\title{
No more infant formula advertising in The BMJ
}

\author{
Fiona Godlee
}

The BMJ

This week we announced our decision to stop carrying advertisements for formula milk (doi:10.1136/bmj.11200). Regular readers of The $B M J$ will have seen our recent investigation by Chris van Tulleken showing the extent of ties between formula milk manufacturers and the authors of guidelines on cow's milk protein allergy (doi:10.1136/bmj. $\mathrm{k} 5056$ ). The resultant overdiagnosis and overtreatment of this poorly defined condition are among many contributors to falling rates of breastfeeding around the world.

The decision to stop taking the advertisements has been an interesting journey for us. In the process of commissioning and preparing van Tulleken's article for publication we were reminded of the substantial harms caused by aggressive promotion of breast milk substitutes and the biases introduced into research and clinical practice by industry influence. We also improved our understanding of the WHO code on promotion of infant formula, how this is routinely flouted by formula companies, and what it would take for us to comply.

Support from our commercial colleagues and from the BMA has been immensely helpful, as has close collaboration with the Royal College of Paediatrics and Child Health and the British Society of Gastroenterology, with whom we co-own journals. We also asked for input from readers and have been encouraged by your support. The ads won't stop immediately, as we are honouring existing contracts, so you will see them in print and online for the next few months.

Stopping these advertisements in The BMJ and our sister journals doesn't mean we are embarking on an anti-formula campaign. Formula milks are essential for children with complex medical or nutritional needs and for women who aren't able to breastfeed. But the WHO code is clear that decisions on when and how to use them should be based on unbiased sources of information rather than promotional commercial advertising.

We believe that stopping the ads is the right thing to do, not least because it frees us to work with others to get the WHO code into law, to actively promote and support breastfeeding through educational articles, and to campaign against the financial conflicts of interest that fuel industry influence. Instead of being part of the problem we want to be part of the solution.

There is of course a financial hit. We estimate lost revenue of about $£ 300000$ ( $€ 350000 ; \$ 400000)$ across the BMJ company in 2020. But we hope that we will be able to recoup at least some of that loss, with guidance from organisations such as the Human Milk Foundation. They tell us that there will be other organisations-advertisers and funders-who will want to publicly support us in our efforts to improve breastfeeding rates around the world. 